\title{
PENGARUH PRODUK DAN PELAYANAN TERHADAP KEPUASAN KONSUMEN PADA KSPPS BMT AMANAH RAY MEDAN
}

\author{
Hendarto Hidayat, Cece, Edi Winata \\ Alumni Sekolah Tinggi Ilmu Manajemen Sukma \\ Program studi Manajemen, Sekolah Tinggi Ilmu Manajemen \\ cecestim@gmail.com, ediwinatarivail1960@gmail.com
}

\begin{abstract}
The purpose of this research is to know how much influence product and service to customer satisfaction at KSPPS BMT Amanah Ray Medan. The samples are 80 customer KSPPS BMT Amanah Ray Medan, using random sampling. Random sampling is that provides an equal opportunity for every member of the population to be sample. Data analysis using multiple regression test the accuracy of the model (the classical assumption), hypothesis testing use the coefficient of determination $\left(R^{2}\right)$, partial test ( $t$ test), and simultaneous test (F test), data processing use SPSS 20. The results showoff the coefficient of determination $\left(R^{2}\right)$ variable product and service are able to explain the existence of the variable customer satisfaction. Partial test, product and service have positive and significant effectto customer satisfaction. Simultaneous test, product and service have positive and significant effect to customer satisfaction.

Keywords : Product, service, and customer satisfaction.
\end{abstract}

\section{PENDAHULUAN}

Keberagaman produk yang ditawarkan produsen membuat kita sebagai konsumen dapat memilih sendiri produk yang sesuai dengan kebutuhan dan keinginan kita.Membenahi, berinovasi dan mendengarkan apa yang dikatakan konsumen menjadi kunci keberhasilan suatu produk dan jasa baik yang sedang maupun yang akan dikembangkan. Seperti yang kita ketahui bahwa tawaran produk dan jasa sudah sangat beragam dewasa ini, terutama pada bagian lembaga keuangan.Selain menawarkan produk tentunya lembaga keuangan juga memberikan pelayanan terhadap nasabahnya.Dari sudut pandang konsumen, produk dan kualitas pelayanan sering dijadikan indikator dalam untuk memilih sesuatu.Produk adalah sesuatu yang dapat atau tidak dilihat wujudnya. Produk yang baik tentunya akan didasari oleh pelayanan yang baik yang diberikan oleh penjualnya. Pelayanan adalah hal yang diberikan oleh seseorang sehingga membuat orang lain merasa diperhatikan.Kepuasan konsumen adalah rasa yang ditimbulkan oleh konsumen atas penggunaan atau pembelian suatu barang.Produk dan pelayanan yang baik akan berdampak pada kepuasan konsumen.

Penelitian yang dilakukan oleh Prasastono dan Pradapa (2012) menyimpulkan bahwa adanya pengaruh positif dan signifikan antara kualitas produk dan kualitas pelayanan terhadap kepuasan konsumen.Penelitian yang dilakukan Saidani dan Arifin (2012) menyimpulkan bahwa kualitas produk dan kualitas pelayanan berpengaruh terhadap keputusan konsumen dan minat beli.

\section{Perumusan Masalah}

Perumusan masalah penelitian ini adalah:

1. Apakah ada pengaruh produk terhadap kepuasan konsumen pada KSPPS BMT Amanah Ray Medan? 
2. Apakah ada pengaruh pelayanankepuasan konsumen pada KSPPS BMT Amanah Ray Medan?

3. Apakah ada pengaruh produk dan pelayanan terhadap kepuasan konsumen pada KSPPS BMT Amanah Ray Medan?

\section{Batasan Masalah}

Penelitian ini hanya dibatasi pada nasabah yang berada di pasar Beruang Medan dalam satu minggu.

\section{Tujuan Penelitian}

Adapun tujuan dari penelitian ini adalah untuk mengetahui sejauh manaproduk dan pelayanan dapat memberikan kepuasan konsumen pada KSPPS BMT Amanah Ray Medan.

\section{METODE PENELITIAN}

\section{Tempat dan Waktu Penelitian}

Penelitian ini dilakukan pada KSPPS BMT Amanah Ray Medan yang dilaksanakan pada bulan April 2017.

\section{Jenis dan Sumber Data}

Data yang digunakan dalam penelitian ini adalah data primer dan data sekunder.

1. Data primer adalah sumber data yang secara langsung memberikan data kepada pengumpul data (Sugiyono, 2012:25). Data primer berupa catatan hasil wawancara yang diperoleh melalui wawancara yang penulis lakukan. Selain itu, mengumpulkan data dalam bentuk catatan tentang situasi dan kejadian di perpustakaan.

2. Data sekunder adalah sumber data yang tidak memberikan informasi secara langsung kepada pengumpul data. Sumber data sekunder ini dapat berupa hasil pengolahan lebih lanjut dari data primer yang disajikan dalam bentuk lain atau orang lain (Sugiyono, 2012:25). Data ini digunakan untuk mendukung informasi dari data primer.

Sumber data yang digunakan yaitu:

1. Data Internal

2. Data eksternal

\section{Metode Pengumpulan Data}

Metode pengumpulan data yang digunakan dalam penelitian ini sebagai berikut:

1. Studi Dokumentasi

2. Kuesioner

3. Observasi

\section{Definisi Operasional}

Berdasarkan rumusan masalah, maka variable-variabel dalam penelitian ini dapat diidentifikasi sebagai berikut:

1. Variabel bebas (variabel independen) adalah variabel yang mempengaruhi variabel terikat, yang terdiri dari produk $\left(\mathrm{X}_{1}\right)$ dan pelayanan $\left(\mathrm{X}_{2}\right)$;

2. Variable terikat (variabel dependen) adalah variabel yang dipengaruhi oleh variabel bebas, yaitu kepuasan konsumen (Y). 
Tabel 1. Operasionalisasi Variabel Penelitian

\begin{tabular}{|l|l|l|l|l|}
\hline \multirow{2}{*}{ No } & Variabel & Definisi & Indikator & Skala \\
Ukur
\end{tabular}

Sumber :Daryanto (2013:52), Tjiptono (2012:20), Kotler (2012:49), Tjiptono (2012:32),

Zeithaml dan Bitner (2012:75), Hawkins dan Lonney dalam Tjiptono (2012:50)

\section{Uji Validitas dan Reliabilitas}

Menurut Sugiyono (2012:110) "uji validitas adalah suatu langkah pengujian yang dilakukan terhadap isi dari suatu instrumen, dengan tujuan untuk mengukur ketepatan instrumen yang digunakan dalam suatu penelitian". Dikatakan valid jika nilai rhitung $\geq$ rtabel dan dikatakan tidak valid jika nilai rhitung $<$ rtabel.

Menurut Sugiyono (2012:111) "uji reliabilitas adalah proses pengukuran terhadap ketepatan (konsisten) dari suatu instrumen". Dikatakan reliabel jika nilai crombach alfa $>$ 0,6 dan dikatakan tidak reliable jika nilai crombach alfa< 0,6 .

\section{Metode Analisis Data}

Metode analisis data yang digunakan dalam penelitian ini adalah metode deskriptif kuantitatif, sedangkan model analisis yang digunakan dalam penelitian ini adalah regresi linier berganda, dengan model persamaan: $Y=a+b_{1} X_{1}+b_{2} X_{2}+e$

Dimana:

$$
\begin{array}{ll}
\mathrm{Y} & =\text { Kepuasan konsumen } \\
\mathrm{X}_{1} & =\text { Produk } \\
\mathrm{X}_{2} & =\text { Pelayanan } \\
\mathrm{a} & =\text { Konstanta } \\
\mathrm{b}_{1} & =\text { Koefisien regresi varibel produk } \\
\mathrm{b}_{2} & =\text { Koefisien regresi variabel pelayanan } \\
\mathrm{e} & =\text { Error of term (variabel yang tidak diteliti) }
\end{array}
$$

\section{Kerangka Berpikir}


Produk adalah segala hal yang dapat memenuhi kebutuhan konsumen. Pelayanan yang baik akan membuat suatu produk bernilai baik. Kepuasan konsumen adalah rasa yang ditimbulkan oleh pengguna suatu barang karena sesuai dengan yang konsumen harapkan.Penelitian yang dilakukan oleh Novianti dkk (2015) menunjukkan bahwa kualitas produk dan pelayanan berpengaruh positif dan signifikan terhadap kepuasan konsumen.

\section{Hipotesis}

Hipotesis merupakan jawaban sementara yang memerlukan penelitian lebih lanjut untuk mendapatkan kebenarannya.Hipotesis penelitian ini adalah "ada pengaruh produk dan pelayanan terhadap kepuasan konsumen pada KSPPS BMT Amanah Ray Medan".

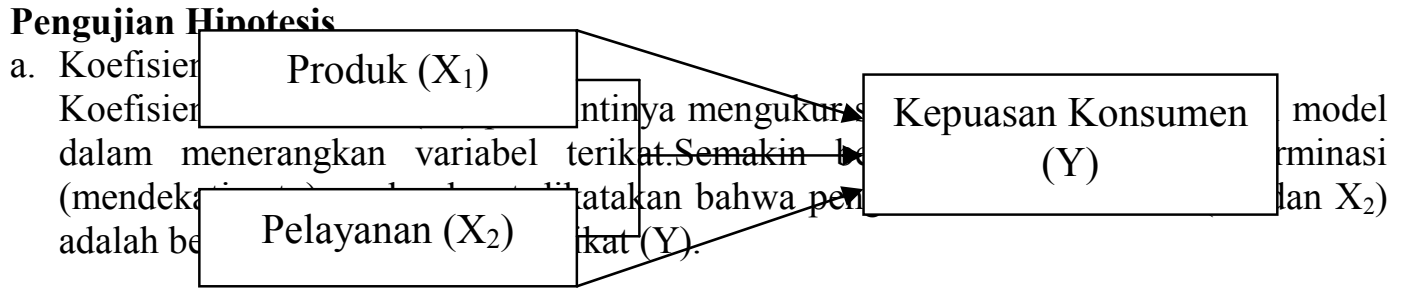

b. Uji Simultan (Uji F)

Untuk menguji hipotesis penelitian ini digunakan uji simultan (uji F), uji ini dilakukan untuk melihat pengaruh produk dan pelayanan secara simultan terhadap kepuasan konsumen, pengujian dilakukan pada tingkat kepercayaan 95\% atau tingkat kesalahan $\alpha=0,05(5 \%)$, dengan kriteria:

1. Jika $\mathrm{F}_{\text {hitung }} \leq \mathrm{F}_{\text {tabel, }}$, maka $\mathrm{H}_{0}$ diterima, $\mathrm{H}_{1}$ ditolak, artinya secara simultan penelitian ini tidak berpengaruh;

2. Jika $\mathrm{F}_{\text {hitung }}>\mathrm{F}_{\text {tabel }}$, maka $\mathrm{H}_{0}$ ditolak, $\mathrm{H}_{1}$ diterima, artinya secara simultan penelitian ini berpengaruh.

c. Uji Parsial (Uji t)

Uji parsial (uji t) bertujuan untuk melihat pengaruh produk dan pelayanan terhadap kepuasan konsumen, dengan kriteria:

1. Jika $t_{\text {hitung }} \leq t_{\text {tabel }}$ maka $\mathrm{H}_{0}$ diterima, $\mathrm{H}_{1}$ ditolak, artinya secara parsial penelitian ini tidak berpengaruh;

2. Jika $t_{\text {hitung }}>t_{\text {tabel }}$ maka $H_{0}$ ditolak, $H_{1}$ diterima, artinya secara parsial penelitian ini berpengaruh.

\section{HASIL PENELITIAN DAN PEMBAHASAN}

\section{Hasil Penelitian}

Data diperoleh dari hasil kuesioner yang diberikan kepada responden memberikan hasil bahwa produk yang ditawarkan berbeda dari yang lain dan sesuai dengan kebutuhan mereka.

\section{Uji Validitas dan Reliabilitas}

Tabel 2. Validitas instrumen variabel Produk $\left(\mathrm{X}_{1}\right)$

\begin{tabular}{|l|l|l|}
\hline \multicolumn{2}{|l|}{ Nilai Validitas } & \multirow{2}{*}{ Kesimpulan } \\
\hline rhitung & rtabel & \\
\hline 0,466 & \multirow{3}{*}{0,221} & Valid \\
0,425 & Valid \\
0,481 & & Valid \\
\hline
\end{tabular}




\begin{tabular}{|l|l|l|}
0,577 & & Valid \\
0,277 & Valid \\
\hline 0,24 & & Valid \\
\hline
\end{tabular}

Dari tabel 2.terlihat bahwa hasil pengujian masing-masing instrument variabel produk $\left(\mathrm{X}_{1}\right)$ memiliki nilai $\mathrm{r}_{\text {hitung }}>\mathrm{r}_{\text {tabel }}$ yaitu 0,221 , dengan demikian dapat disimpulkan bahwa secara keseluruhan instrumen pernyataan dari variabel produk yang digunakan valid.

Tabel 3. Validitas instrumen variabel Pelayanan $\left(\mathrm{X}_{2}\right)$

\begin{tabular}{|l|l|l|l|}
\hline \multirow{2}{*}{ Instrumen } & \multicolumn{2}{|l|}{ Nilai Validitas } & \multirow{2}{*}{ Kesimpulan } \\
\cline { 2 - 2 } & rhitung & rtabel & \\
\hline Pelayanan 1 & 0,228 & & Valid \\
\hline Pelayanan 2 & 0,276 & & Valid \\
\hline Pelayanan 3 & 0,341 & \multirow{4}{*}{0,221} & Valid \\
\hline Pelayanan 4 & 0,432 & & Valid \\
\hline Pelayanan 5 & 0,340 & & Valid \\
\hline Pelayanan 6 & 0,086 & & Valid \\
\hline
\end{tabular}

Dari tabel 3.terlihat bahwa hasil pengujian masing-masing instrumen variabel harga (x2) memiliki nilai $r_{\text {hitung }}>r_{\text {tabel }} 0,221$, dengan demikian dapat disimpulkan bahwa secara keseluruhan instrumen pernyataan dari variabel pelayanan yang digunakan valid.

Tabel 4. Validitas instrumen variabel Kepuasan Konsumen (Y)

\begin{tabular}{|l|l|l|l|}
\hline \multirow{2}{*}{ Instrumen } & \multicolumn{2}{|l|}{ Nilai Validitas } & \multirow{2}{*}{ Kesimpulan } \\
\cline { 2 - 2 } & rhitung & rtabel & \\
\hline Kepuasan Konsumen 1 & 0,345 & & Valid \\
\hline Kepuasan Konsumen 2 & 0,394 & & Valid \\
\hline Kepuasan Konsumen 3 & 0,264 & \multirow{4}{*}{0,221} & Valid \\
\cline { 2 - 2 } Kepuasan Konsumen 4 & 0,409 & Valid \\
\hline Kepuasan Konsumen 5 & 0,296 & & Valid \\
\hline Kepuasan Konsumen 6 & 0,234 & & Valid \\
\hline
\end{tabular}

Dari tabel 4.terlihat bahwa hasil pengujian masing-masing instrument variabel keputusan pembelian (Y) memiliki nilai $r_{\text {hitung }}>r_{\text {tabel }}$ 0,221, dengan demikian dapat disimpulkan bahwa secara keseluruhan instrumen pernyataan dari variabel kepuasan konsumen yang digunakan valid.

\section{Uji reliabilitas}

Tabel 5. Hasil Reliabilitas Instrumen Penelitian

\begin{tabular}{|l|l|l|l|}
\hline No & Variabel & $\begin{array}{l}\text { NilaiCronbach's } \\
\text { Alfa }\end{array}$ & Kesimpulan \\
\hline 1 & Produk $\left(\mathrm{X}_{1}\right)$ & 0,662 & Reliabel \\
\hline 2 & Pelayanan $\left(\mathrm{X}_{2}\right)$ & 0,638 & Reliabel \\
\hline 3 & Kepuasan Konsumen $(\mathrm{Y})$ & 0,673 & Reliabel \\
\hline
\end{tabular}

Hasil uji reliabilitas menunjukkan bahwa nilaiCronbach's Alfa seluruh variabel lebih besar dari 0,6, maka dapat disimpulkan bahwa kuisioner penelitian ini dikatakan reliabel. 


\section{Hasil Uji Regresi Linear Berganda}

Pengujian ini dilakukan untuk mengetahui pengaruh produk dan pelayanan terhadap kepuasan konsumen pada KSPPS BMT Amanah Ray. Berikut ini tabel hasil pengujian regresi linear berganda pada masing-masing variabel yaitu:

Tabel 6.Hasil Uji Regresi Linear Berganda

Coefficients $^{\mathbf{a}}$

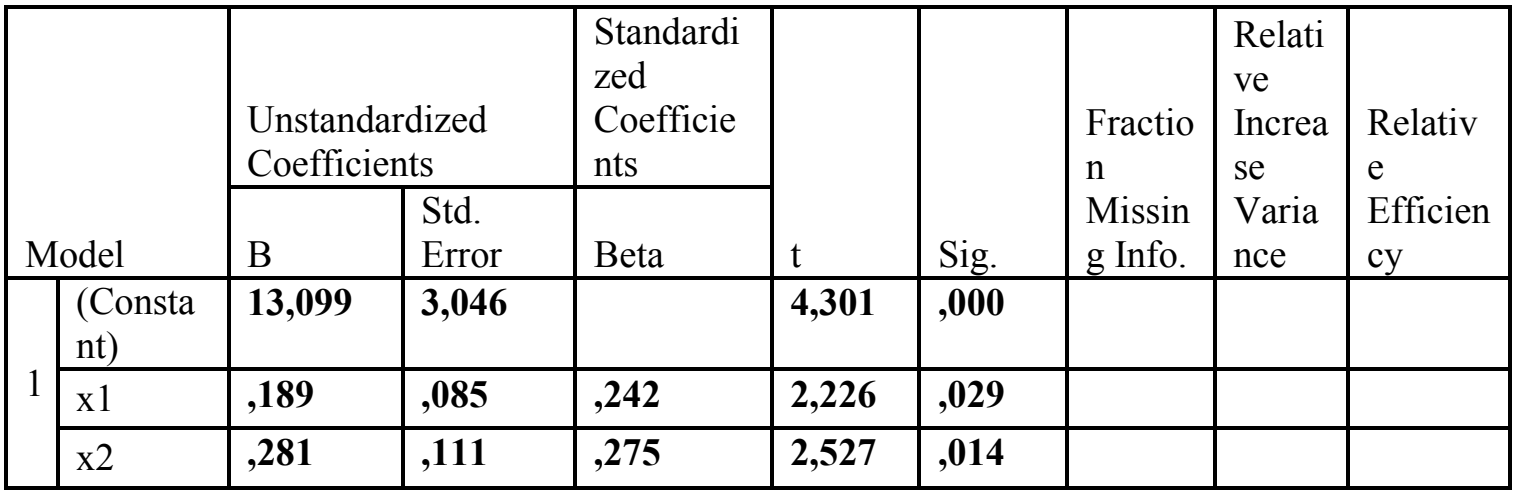

a. Dependent Variable: y

Berdasarkan hasil pengujian diatas, maka diperoleh persamaan regresi linear berganda sebagai berikut: $\mathrm{Y}=13,099+0,189 \mathrm{X} 1+0,281 \mathrm{X} 2$

Pada model regresi linear berganda diperoleh nilai konstanta kepuasan konsumen sebesar 13,099 artinya jika nilai variabel bebas (X1 dan X2) nilainya 0, maka variabel terikat (Y) nilainya sebesar 13,099.Koefisien regresi masing-masing variabel bebas bernilai positif, artinya kepuasan konsumen pada KSPPS BMT Amanah Ray dapat dipengaruhi oleh produk dan pelayanan.

\section{Pengujian Hipotesis}

a. Koefisien Determinasi $\left(\mathrm{R}^{2}\right)$

Tabel 7. Hasil Uji Koefisien Determinasi $\left(\mathrm{R}^{2}\right)$

\begin{tabular}{|l|l|l|l|l|}
\multicolumn{5}{|c|}{ Model Summary } \\
\hline & & & $\begin{array}{l}\text { Std. } \\
\text { Adjusted }\end{array}$ & $\begin{array}{l}\text { Error of } \\
\text { the } \\
\text { Model }\end{array}$ \\
\hline 1 & $\mathrm{R}$ & Square & Square & Estimate \\
\hline
\end{tabular}

a. Predictors: (Constant), $\mathrm{x} 2, \mathrm{x} 1$

Nilai koefisien determinasi yang diperoleh sebesar 0,176 atau $17,6 \%$ menunjukkan bahwa variabel produk dan pelayanan mampu menjelaskan variasi yang terjadi pada kepuasan konsumen pada KSPPS BMT Amanah Ray, sedangkan sisanya 82,4\% dijelaskan oleh variabel lain yang tidak diteliti dalam penelitian ini seperti promosi yang diberikan, lokasi dan lainnya.

b. Uji Simultan (uji F)

Tabel 8. Hasil Uji Simultan (Uji F)

ANOVA $^{\mathrm{a}}$

\begin{tabular}{|l|l|l|l|l|l|}
\hline Model & $\begin{array}{l}\text { Sum of } \\
\text { Squares }\end{array}$ & df & $\begin{array}{l}\text { Mean } \\
\text { Square }\end{array}$ & F & Sig. \\
\hline
\end{tabular}




\begin{tabular}{|l|l|l|l|l|l|l|}
\multirow{4}{*}{1} & Regression & $\mathbf{3 9 , 6 1 5}$ & $\mathbf{2}$ & $\mathbf{1 9 , 8 0 8}$ & $\mathbf{8 , 2 0 6}$ & $\mathbf{, 0 0 1}^{\mathbf{b}}$ \\
\cline { 2 - 7 } & Residual & $\mathbf{1 8 5 , 8 7 2}$ & $\mathbf{7 7}$ & $\mathbf{2 , 4 1 4}$ & & \\
\cline { 2 - 7 } & Total & $\mathbf{2 2 5 , 4 8 8}$ & $\mathbf{7 9}$ & & & \\
\hline
\end{tabular}

a. Dependent Variable: y

b. Predictors: (Constant), x2, x1

Berdasarkan tabel tersebut dapat dilihat bahwa nilai $\mathrm{F}_{\text {hitung }}$ yaitu 8,206 $>$ dari nilai $\mathrm{F}_{\text {tabel }}$ yaitu 2,72 dan nilai signifikan $0,01<$ dari nilai alpha 0,05 . Maka keputusan yang diambil $\mathrm{H}_{0}$ ditolak $\mathrm{H}_{1}$ diterima. Dengan diterimanya $\mathrm{H}_{1}$ menunjukkan bahwa variabel bebas yang terdiri dari produk $\left(\mathrm{X}_{1}\right)$ dan pelayanan $\left(\mathrm{X}_{2}\right)$ mampu menjelaskan keragaman variabel terikat $(\mathrm{Y})$, dengan demikian variabel produk dan pelayanan secara simultan berpengaruh positif dan signifikan terhadap kepuasan konsumen pada KSPPS BMT Amanah Ray.

c. Uji Parsial (uji t)

Tabel 9. Hasil Uji Parsial (Uji t)

Coefficients $^{\mathrm{a}}$

\begin{tabular}{|c|c|c|c|c|c|c|}
\hline \multirow{2}{*}{\multicolumn{2}{|c|}{ Model }} & \multicolumn{2}{|c|}{$\begin{array}{l}\text { Unstandardized } \\
\text { Coefficients }\end{array}$} & \multirow{2}{*}{$\begin{array}{l}\text { Standardized } \\
\text { Coefficients } \\
\text { Beta }\end{array}$} & \multirow[b]{2}{*}{$\mathrm{t}$} & \multirow[b]{2}{*}{ Sig. } \\
\hline & & B & $\begin{array}{l}\text { Std. } \\
\text { Error }\end{array}$ & & & \\
\hline \multirow{3}{*}{1} & (Constant) & 13,099 & 3,046 & & 4,301 &, 000 \\
\hline & $\mathrm{x} 1$ & ,189 & ,085 & ,242 & 2,226 & ,029 \\
\hline & $x 2$ & ,281 & ,111 & ,275 & 2,527 & ,014 \\
\hline
\end{tabular}

a. Dependent Variable: $y$

Berdasarkan tabel tersebut dapat dilihat bahwa:

1. Nilai $t_{\text {hitung }}$ untuk variabel produk2,226 $>t_{\text {tabel }} 1,991$ dan nilai signifikan $0,029<$ dari alpha 0,05 , maka $\mathrm{H}_{0}$ ditolak dan $\mathrm{H}_{1}$ diterima, dengan demikian secara parsial variabel produk berpengaruh positif dan signifikan terhadap kepuasan konsumen.

2. Nilai $t_{\text {hitung }}$ untuk variabel pelayanan $2,527>t_{\text {tabel }} 1,991$ dan nilai signifikan $0.014<$ dari nilai alpha 0,05 , maha $\mathrm{H}_{0}$ ditolak dan $\mathrm{H} 1$ diterima, dengan demikian secara parsial variabel pelayanan berpengaruh positif dan signifikan terhadap keputusan pembelian.

\section{Pembahasan}

Hasil pengujian hipotesis pertama menunjukkan bahwa variabel produk dan pelayanan mampu menjelaskan variasi yang terjadi pada kepuasan komsumen di KSPPS BMT Amanah Ray, ini dibuktikan dengan nilai koefisien determinasi $\left(\mathrm{R}^{2}\right)$ yang diperoleh sebesar 0,176 atau $17,6 \%$, sedangkan sisanya sebesar $82,4 \%$ dijelaskan oleh variabel lain yang tidak diteliti dalam penelitian ini.

Hasil pengujian hipotesis menunjukkan bahwa variabel produk dan pelayanan secara simultan dan parsial berpengaruh positif dan signifikan terhadap keputusan pembelian pada STIM Sukma, ini dibuktikan dengan nilai $\mathrm{F}_{\text {hitung }} 8,206>\mathrm{F}_{\text {tabee }} 2,72$ dengan nilai signifikan $0.001<$ dari nilai alpha 0,05 dan nilai $t_{\text {hitung }} 2,226\left(\mathrm{X}_{1}\right)$ dan 2,527 $\left(\mathrm{X}_{2}\right)>\mathrm{t}_{\text {tabel }}$ 1,991 dengan tingkat signifikan 0,029 dan $0,014<$ dari alfa 0,005 . Hasil penelitian ini sesuai dengan hasil penelitian yang dilakukan oleh Novianti dkk (2015) yang berjudul "Pengaruh Kualitas Produk dan Pelayanan Terhadap Kepuasan Konsumen", hasil penelitiannya menunjukkan bahwa secara simultan dan parsial kualitas produk dan pelayanan berpengaruh positif dan signifikan terhadap kepuasan konsumen. 


\section{KESIMPULAN}

Berdasarkan hasil penelitian dan pembahasan pada bab sebelumnya, maka dapat disimpulkan sebagai berikut:

1. Secara simultan produk dan pelayanan berpengaruh positif dan signifikan terhadap kepuasan konsumen pada KSPPS BMT Amanah Ray;

2. Secara parsial variabel produk berpengaruh terhadap kepuasan konsumen dan variabel pelayanan berpengaruh terhadap kepuasan konsumen;

3. Konsumen merasa puas menggunakan produk yang ditawarkan oleh KSPPS BMT Amanah Ray karena produk yang ditawarkan sesuai dengan kebutuhan mereka. 


\section{REFERENCES}

Cece. (2003). Analisis Hubungan Perencanaan Strategi Aliansi PDAM Tirtanadi-PT. Telekominikasi Divre I Terhadap Peningkatan Kualitas Pelayanan Pelanggan PDAM Tirtanadi... Universitas Sumatera Utara.

Daryanto.(2013). Sari Kuliah Manajemen Pemasaran (II). Bandung: PT. Sarana Tutorial Nurani Sejahtera.

Dewi, S. P., \& Hidayat, R. (2014). Pengaruh Net Profit Margin dan Return on Assets terhadap Harga Saham pada Perusahaan Otomotif yang terdaftar di Bursa Efek Indonesia. Jurnal Ilman, 1(1), 1-10.

Dinamika, S. G., \& Siregar, E. B. A. (2016). Developing English Syllabus for Tourism Management Students. In Proceedings of the Fourth International Seminar on English Language and Teaching (ISELT-4) (Vol. 13, pp. 16-17).

Fathimah, V. (2017). Pengaruh Perkembangan Jumlah Tabungan, Deposito dan Bagi Hasil terhadap Jumlah Pembiayaan yang Diberikan oleh Perbankan Syariah di Sumatera Utara. Jurnal Ilman, 5(1), 41-52.

Hidayat, R. (2010). Analisis Tingkat Penggunaan Internet Dikalangan Mahasiswa dan Hubungannya dalam Peningkatan Nilai Akademik (Studi Kasus pada Mahasiswa di Kota Medan). Jurnal Mediasi, 2(2), 55-63.

Hidayat, R. (2015). Performance Appraisal sebagai Alat Pengukuran Kepuasan Kerja Karyawan. Jurnal Ilman, 3(1), 1-8.

Keller, K. L., \& Kotler, P. (2012).Marketing Management (14th ed.). New Jersey: Pearson Prestice Hall.

Kotler, P. (2012). Manajemen Pemasaran Persfektif Asia (Pertama). Yogyakarta: Andi.

Kotler, P., \& Amstrong, G. (2012).Prinsip-Prinsip Pemasaran (13th ed.). Jakarta: Erlangga.

Nasution, W. A. (2009). Pengaruh kepuasan kerja karyawan terhadap intensi turnover pada call center Telkomsel di Medan. Jurnal Mandiri, 4(1), 1-11.

Nasutiona, L. K., Fahrurb, M., Christine, Imaduddind, \& Wardayani. (2017). The Calculation of Cost of Goods Sold "Gayo Arabica Coffee from Takengon" with Variable Costing Method. Journal Online Jaringan COT POLIPD (JOJAPS), 10, 82-87.

Ningratri, Y. A. (2017). Analisis Pengaruh Strategi Bauran Pemasaran Jasa (3P) terhadap Keputusan Mahasiswa Memilih STIM Sukma Medan. Riset \& Ejurnal Manajemen Informatika, 3(1), 50-56.

Novianti, R., Iskandar, \& Adawiyah, R. (2015).Pengaruh Kualitas Produk dan Pelayanan Terhadap Kepuasan Konsumen Pada Depo Air Minum Isi Ulang Water Jaya di Tenggarong.JEMI, 15(1), 27-34.

Prana, R. R. (2016). Analisis Faktor-faktor yang Mempengaruhi Pendapatan Asli Daerah (PAD) Kota Tebing Tinggi. Jurnal Ilman, 4(1), 74-86.

Prasastono, N., \& Pradapa, S. Y. F. (2012).Kualitas Produk dan Kulaitas Pelayanan Terhadap Kepuasan Konsumen Kentucky Fried Checken Semarang Candi.Dinamika Kepariwisataan, XI(2), 13-23. 
Saidani, B., \& Arifin, S. (2012). Pengaruh kualitas produk dan kualitas layanan terhadap kepuasan konsumen dan minat beli pada ranch market, 3(1), 1-22.

Sinuhaji, E. (2010). PENERAPAN LAYANAN UNGGUL DALAM PEMASARAN PRODUK BANK. Jurnal Mediasi, 2(1).

Sugiyono.(2012). Metode Penelitian Bisnis (Pendekatan Kuantitatif, Kualitatif dan $R \& D)$. Bandung: Alfabeta.

Sukendro, H. A. (2012). Pengaruh Citra Merek dan Kualitas Pelayanan terhadap Kepuasan Jama'ah pada Kelompok Bimbingan Ibadah Haji (KBIH) Indosat Medan. Universitas Terbuka.

Tjiptono, F. (2012).Service Manajemen Mewujudkan Pelayanan Prima. Yogyakarta: CV. Andi Offset.

Wardayani. (2013). Pengaruh Pengetahuan Dewan Tentang Anggaran, Partisipasi Masyarakat dan Transparansi Kebijakan Publik terhadap Kinerja DPRD dalam Pengawasan Keua. Jurnal BIS-A Politeknik LP3i Medan, 2, 35-45.

Widjanarko, B. (2015). PENGARUH PEMERIAN KOMPENSASI DAN KOMUNIKASI TERHADAP SEMANGAT KERJA KARYAWAN PADA BUMI KARYA TAMA INSURANCE CABANG MEDAN. Jurnal Research Sains, 1(2), $130-152$.

Winata, E. (2015). Pengaruh Disiplin Kerja dan Budaya Kerja terhadap Semangat Kerja Karyawan pada PT. Mayasari Binangun Medan. Research Sains, 1(2), 100-117.

Winata, E. (2017). PENGARUH BAURAN PEMASARAN JASA TERHADAP LOYALITAS KONSUMEN PADA GRAND SERELA HOTEL \& CONVENTION MEDAN. Jurnal Mutiara Manajemen, 1(1), 109-121.

Zeithml,\& Bitner. (2012). The Concept of Customer Satisfaction. USA: The McGraw Hill-Companies.

Zuhri, \& Pertiwi, L. S. (2016). Airline revenue management under number of no-shows uncertainty. Global Journal of Pure and Applied Mathematics, 12(1), 1003-1012.

Zuhri. (2015). Model Input Output dan Aplikasinya pada Enam Sektor. Jurnal Ilman, $3(1), 16-21$. 